\section{Food habits and temporal activity patterns of the Golden Jackal Canis aureus and the Jungle Cat Felis chaus in Pench Tiger Reserve, Madhya Pradesh, India}

\author{
Aniruddha Majumder ${ }^{1}$, K. Sankar ${ }^{2}$, Qamar \\ Qureshi ${ }^{3}$ \& Santanu Basu ${ }^{4}$ \\ 1,2,3,4 Wildlife Institute of India, P.O, Box 18, Dehradun, \\ Uttarakhand 248001, India \\ Email: ${ }^{1}$ aniruddha@wii.gov.in (corresponding author), \\ 22sankark@wii.gov.in, ${ }^{3}$ qnq@wii.gov.in, ${ }^{4}$ santanubasu2k6@ \\ gmail.com
}

The ability of ecologically similar species to coexist depends largely on the degree to which resources are limiting and how resources can be partitioned as the species become sympatric (Schoener 1974). Empirical studies dealing with mammalian carnivores showed that coexisting carnivores tend to have different dietary and activity patterns, indicating that it is a common phenomenon for coexisting species to have different niches (Maddock \& Perrin 1993; Tatara \& Doi 1994). In India, most of the studies on dietary and temporal activity patterns of carnivores have been carried out on large carnivores (Johnsingh 1983; Karanth \& Sunquist 1995; Biswas \& Sankar 2002; Andheria

Date of publication (online): 26 November 2011

Date of publication (print): 26 November 2011

ISSN 0974-7907 (online) | 0974-7893 (print)

Editor: Shomen Mukherjee

Manuscript details:

Ms \# o2713

Received 20 February 2011

Final received 17 September 2011

Finally accepted 20 October 2011

Citation: Majumder, A., K. Sankar, Q. Qureshi \& S. Basu (2011). Food habits and temporal activity patterns of the Golden Jackal Canis aureus and the Jungle Cat Felis chaus in Pench Tiger Reserve, Madhya Pradesh, India. Journal of Threatened Taxa 3(11): 2221-2225.

Copyright: @ Aniruddha Majumder, K. Sankar, Qamar Qureshi \& Santanu Basu 2011. Creative Commons Attribution 3.0 Unported License. JoT allows unrestricted use of this article in any medium for non-profit purposes, reproduction and distribution by providing adequate credit to the authors and the source of publication.

Acknowledgements: We are thankful to the Madhya Pradesh Forest Department, National Tiger Conservation Authority (NTCA), Director and Dean of Wildlife Institute of India for their support to carry out field study in Pench. Mr. Vinod Thakur, Gurhanlal and Brijlal are also acknowledged for their assistance in the laboratory and in the field. et al. 2007; Edgaonkar 2008; Ramesh et al. 2009) and very few studies were carried out on mesocarnivores (Sankar 1988; Mukherjee 1989; Balasubramanian \& Bole 1993; Mukherjee et al. 2004; Aiyadurai \& Jhala 2006).

Food habits and temporal activity patterns of the Golden Jackal Canis aureus and the Jungle Cat Felis chaus were studied between January 2008 and June 2009 in Pench Tiger Reserve (PTR) (79009'-79²2'E \& 21038-21050’N), Madhya Pradesh, central India. Pench Tiger Reserve connects Kanha with Satpura Tiger Reserve and forms a continuous forest patch in central India which offers one of the important habitats of large and meso-carnivores in the Indian subcontinent (Biswas \& Sankar 2002; Qureshi et al. 2006; Acharya et al. 2007). The overall goal of the present study is (i) to determine the frequency of occurrence of different food items in the diet of these two meso-carnivores in PTR, (ii) to examine the implications of these diet profiles and temporal activity for understanding resource partitioning patterns and ecological sympatry among them in PTR.

The Pench Tiger Reserve comprises a national park $\left(292 \mathrm{~km}^{2}\right)$, a sanctuary $\left(118 \mathrm{~km}^{2}\right)$ and a reserved forest $\left(348 \mathrm{~km}^{2}\right)$ covering an area of the $758 \mathrm{~km}^{2}$. Vegetation in the area is broadly classified as having both tropical dry deciduous and tropical moist deciduous forests (Champion \& Seth 1968). Teak (Tectona grandis L.) and its associated species in the area represent a transition from tropical dry deciduous to tropical moist deciduous forests. The terrain is undulating in most areas of the tiger reserve (Biswas \& Sankar 2002). Pench experiences markedly seasonal climate with a distinct summer (March-June), monsoon (July-September) and winter (October-February) and receives a mean annual rainfall of c. $1400 \mathrm{~mm}$. The temperature ranged from $2^{\circ} \mathrm{C}$ in winter to $49.5^{\circ} \mathrm{C}$ in summer during the study period.

The Golden Jackal (body weight 8-11 kg) (Prater 1980; Giannatos 2004) ranges from northern Africa and extends across the middle-east to India. The species is included in CITES Appendix II and Schedule III in the Wildlife (Protection) Act 1972 of India. The Jungle Cat (body weight 5-6 kg) has established itself over a wide range from northern Africa through south-western Asia to India, Ceylon and Indo-China 
(Prater 1980). It is included in CITES Appendix II and Schedule II of the Indian Wildlife (Protection) Act 1972. Apart from the Golden Jackal and the Jungle Cat, other carnivore species found in the study area are Tiger Panthera tigris, Leopard Panthera pardus, Dholes Cuon alpinus, Palm Civet Paradoxurus hermaphrodites, Ratel Mellivora capensis, Small Indian Civet Viverricula indica, Common Mongoose Herpestes edwardsii and Ruddy Mongoose Herpestes smithii (Biswas \& Sankar 2002). Rodent species found in the study area are Indian Gerbil Tatera indica, Flat Haired Mouse Mus platythrix and Bush Rat Golunda ellioti (Dungariyal 2008).

The diets of the Golden Jackal and the Jungle Cat can be studied through scat analysis (Reynolds \& Aebischer 1991; Mukherjee et al. 1994; Mukherjee et al. 2004). A total of 50 Golden Jackal scats and 85 Jungle Cat scats were collected wherever encountered from the intensive study area $\left(292 \mathrm{~km}^{2}\right)$. Scats were mostly collected on roads (65\% Golden Jackal scats and 56\% Jungle Cat scats), trails (19\% Golden Jackal scats and $34 \%$ Jungle Cat scats) and dry stream beds (16\% Golden Jackal scats and 10\% Jungle Cat scats). Jackal and Jungle Cat scats were identified by their size, shape and associated signs (Weaver \& Fritts 1979; Green \& Flinders 1981; Danner \& Dodd 1982; Mukherjee et al. 2004). Scats, once collected from the field were washed and dried. Hair and prey remains were compared with reference slides and other body parts of different prey species available at the Wildlife Institute of India laboratory.

We used Pianka's index (Pianka 1973) for measuring diet overlap between predators.

$$
\mathrm{O}_{\mathrm{AB}}=\Sigma \mathrm{pi}_{\mathrm{A}}{ }_{\mathrm{A}} \mathrm{p}_{\mathrm{iB}} /\left(\Sigma \mathrm{p}^{2}{ }_{\mathrm{iA}} \mathrm{p}^{2}{ }_{\mathrm{iB}}\right)^{1 / 2}
$$

where, $p i$ is the relative frequency of prey item $i$ in the diet of species A and $\mathrm{B}$. This index $(\mathrm{O})$ ranges in value from 0 (indicating no overlap) and 1 (complete overlap).

Information on temporal activity pattern was obtained using camera traps (Gompper et al. 2006; Long et al. 2008). Fifty-two pairs of self-triggered analog cameras (DEER CAM ${ }^{\mathrm{TM}}$ ) were deployed in each $2 \mathrm{~km}$ $\mathrm{x} 2 \mathrm{~km}$ grid in the intensive study area $\left(21.07^{\circ}-21.08^{\circ} \mathrm{N}\right.$ \& $79.02^{\circ}-79.5^{\circ} \mathrm{E}$ ), close to animal trails, between March and June for two successive years. Entire camera trap area $\left(>250 \mathrm{~km}^{2}\right)$ covered a homogeneous teak-mixed and undulating habitat. The cameras had a $35 \mathrm{~mm}$ lens, and recorded the date and time of each photograph. The camera delay we kept at a minimum (15 seconds) and sensor activity was set high. We maximized our effort to select the best site for deploying camera traps as per sign intensity of study species and no bait was used to attract the animals. Based on the exact time of the photo-capture for the total number of identified individuals of Golden Jackal and Jungle Cat were pooled into six time categories: 12:00-16:00 hr; 16:01-20:00 hr; 20:01-00:00 hr; 00:01-04:00 hr; 04:01-08:00 hr and 08:01-12:00 hr.

Student t-test (Zar 1984) showed no significant difference on both dietary $(\mathrm{p}=0.06)$ and activity pattern $(p=0.08)$ of these two meso-carnivores between two seasons (summer and winter) so we pooled the data of both into one to analyze them for the present study. The analysis of scats revealed the presence of 10 prey species in the Golden Jackal and eight prey species in the Jungle Cat diets (Table 1). Rodents contributed the maximum in the diet of the two predators $(40 \%$ in Golden Jackal and 63.6\% in Jungle Cat). In Jackal scats, $86 \%$ contained single prey type, $12 \%$ contained two prey types and $2 \%$ contained three prey types. For Jungle Cat scats, $84.7 \%$ of the scats contained single prey type, $14.1 \%$ contained two prey types and $1.2 \%$ contained three prey types. The estimated dietary overlap between jackal and jungle cat was $0.9(90 \%)$ (Table 2).

Table 1. Percentage frequency of food items recorded in scats of Golden Jackal and Jungle Cat in Pench Tiger Reserve, Madhya Pradesh.

\begin{tabular}{|l|c|c|c|c|}
\hline Food item & $\begin{array}{c}\text { No. of } \\
\text { scats } \\
\text { (Golden } \\
\text { Jackal) }\end{array}$ & $\begin{array}{c}\% \text { fre- } \\
\text { quency } \\
\text { of occu- } \\
\text { rrence }\end{array}$ & $\begin{array}{c}\text { No. of } \\
\text { scats } \\
\text { (Jungle } \\
\text { Cat) }\end{array}$ & $\begin{array}{c}\% \text { fre- } \\
\text { quency } \\
\text { of occu- } \\
\text { rrence }\end{array}$ \\
\hline Rodents & 22 & 40 & 63 & 63.6 \\
\hline $\begin{array}{l}\text { Langur Semno- } \\
\text { pithecus entellus }\end{array}$ & 3 & 5.4 & 1 & 1 \\
\hline $\begin{array}{l}\text { Hare Lepus } \\
\text { nigricollis }\end{array}$ & 6 & 10.9 & 11 & 11.1 \\
\hline Chital Axis axis & 13 & 23.6 & 6 & 6.1 \\
\hline $\begin{array}{l}\text { Sambar Rusa } \\
\text { unicolor }\end{array}$ & 1 & 1.8 & 2 & 2 \\
\hline $\begin{array}{l}\text { Nilgai Bosephalus } \\
\text { tragocamelus }\end{array}$ & 2 & 3.6 & 0 & 0 \\
\hline $\begin{array}{l}\text { Wild Pig Sus } \\
\text { scrofa }\end{array}$ & 1 & 1.8 & 1 & 1 \\
\hline Birds & 2 & 3.6 & 7 & 7.1 \\
\hline Reptiles & 4 & 7.2 & 8 & 8.1 \\
\hline Cattle & 1 & 1.8 & 0 & 0 \\
\hline
\end{tabular}

0 - Not present 
Table 2. Dietary overlap between Golden Jackal and Jungle Cat as shown by scat analysis in Pench Tiger Reserve, Madhya Pradesh.

\begin{tabular}{|l|c|c|c|c|c|}
\hline Food items & $\mathbf{p}_{\text {iA }}$ & $\mathbf{p}_{\text {iB }}$ & $\mathbf{C}$ & $\mathbf{D}$ & $\mathbf{E}$ \\
\hline Rodents & 40 & 63.6 & 2544 & 1600 & 4044.9 \\
\hline Langur & 5.5 & 1 & 5.4 & 29.7 & 1 \\
\hline Hare & 10.9 & 11.1 & 121.1 & 119.1 & 123.2 \\
\hline Chital & 23.6 & 6.1 & 144.2 & 558.6 & 37.2 \\
\hline Sambar & 1.8 & 2 & 3.6 & 3.3 & 4 \\
\hline Wild pig & 1.8 & 1 & 1.8 & 3.3 & 1 \\
\hline Birds & 3.6 & 7.1 & 25.8 & 13.2 & 50.4 \\
\hline Reptiles & 7.3 & 8.1 & 58.9 & 52.8 & 65.6 \\
\hline & & & $2904.9(\mathrm{~F})$ & $2380.2(\mathrm{G})$ & $4327.4(\mathrm{H})$ \\
\cline { 4 - 6 } & & & $48.7(\mathrm{I})$ & $65.7(\mathrm{~J})$ \\
\cline { 4 - 6 } & & & & $0.90(\mathrm{~L})$ \\
\hline
\end{tabular}

$\mathrm{p}_{\mathrm{iA}}$ - percentage of food item $\mathrm{i}$ in the diet of golden jackal; $\mathrm{p}_{\mathrm{iB}}$ - percentage of food item $i$ in the diet of jungle cat; $C=p_{i A}{ }^{*} p_{i B} ; D=p_{A}{ }^{\wedge} 2 ; E=p_{B}{ }^{\wedge} 2$; $\mathrm{F}=\sum \mathrm{C} ; \mathrm{G}=\sum \mathrm{D}$ and $\mathrm{H}=\sum \mathrm{EI}=\mathrm{G}^{\wedge} 0.5 ; \mathrm{J}=\mathrm{H}^{\wedge} 0.5, \mathrm{~L}=\mathrm{F} /\left(\mathrm{I}^{*} \mathrm{~J}\right) ; \mathrm{L}=$ Dietary overlap.

Eight-thousand-five-hundred-and-sixty camera trap nights revealed 49 Golden Jackal captures and 189 Jungle Cat captures. G-test showed (Zar 1984), Golden Jackal and Jungle Cat had different activity patterns $\left(\chi^{2}=28.6\right.$, degree of freedom or $\left.\mathrm{df}=5, \mathrm{P}=0.0005\right)$ (Fig. 1). The Golden Jackal had two major activity peaks, one in the early morning (04:01-08:00 hr) and the other at night (20:01-00:00 hr). The Jungle Cat was found active mostly in the night hours (20:01-00:00 $\mathrm{hr})$ and (00:01-04:00 hr).

Scat analysis revealed that these two meso-carnivores primarily consumed mammals ( $>80 \%)$. Rodents formed the most important prey in their diet especially in the case of the Jungle Cat (Table 1, Image 1). The nocturnal habits of the Jungle Cat might be one of the reasons why they consume more rodents which are largely nocturnal as compared to the Golden Jackal. A similar observation was made by Mukherjee et al. (2004) in Sariska Tiger Reserve. The Golden Jackal also might have scavenged on carcasses of large and medium sized mammals such as Chital Axis axis, Sambar Rusa unicolor, Nilgai Bosephalus tragocamelus, Wild Pig Sus scrofa and Common Langur Semnopithecus entellus (Image 2). As the Golden Jackal is a group living canid (Lanszki \& Heltai 2010) the observed hairs of Chital in the jackal diet might also be the result of predation on chital fawn. On several occassions, jackals were found chasing chital fawns

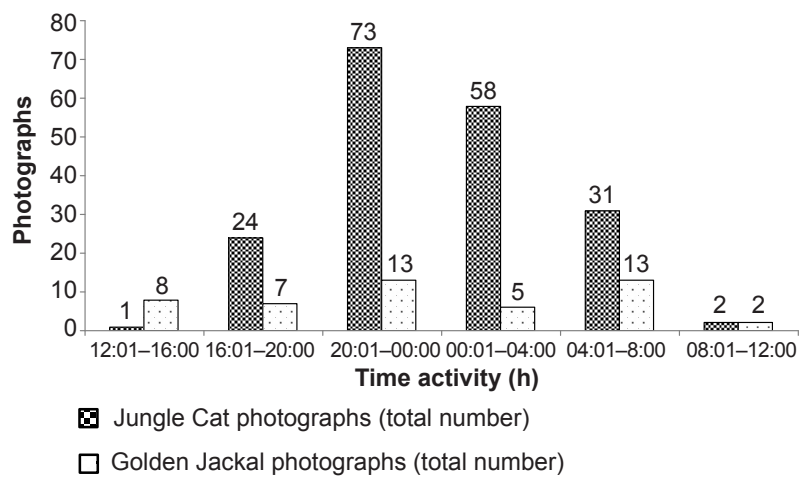

Figure 1. Golden Jackal and Jungle Cat overall temporal activity pattern in Pench Tiger Reserve, as determined from camera trap data.

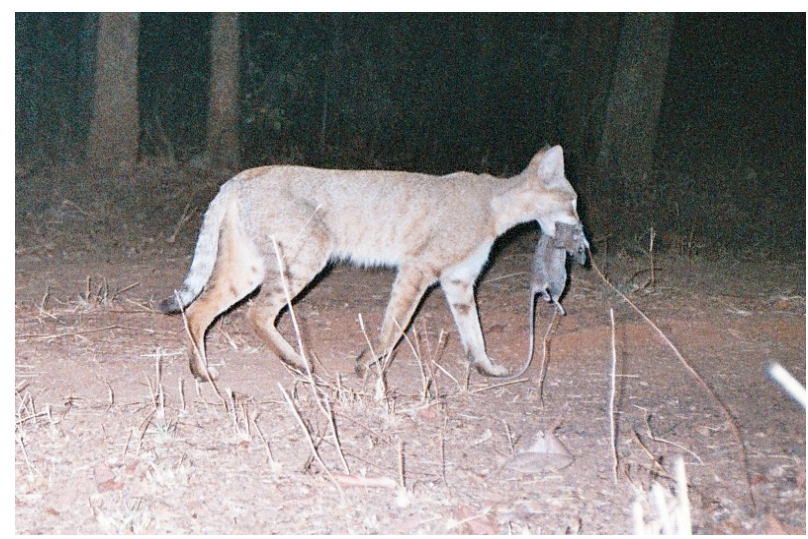

Image 1. Jungle Cat carrying a rodent in Pench Tiger Reserve, Madhya Pradesh.

and killing them in the study area. Though there was no livestock grazing in the study area, the observed occurrence of livestock remains in Golden Jackal scats during the study period were possibly due to scavenging in surrounding villages. Remains of reptiles and rodents up to species level could not be identified in the scats of jackal and jungle cat because of time constraints. Remains of birds such as doves Streptopelia sp. and partridges (Francolinus sp.) were identified in the scats of the jackal and the jungle cat. Seeds of Dyosphyros melanoxylon and Zyzyphus mauritiana were identified in jackal scats. Similar findings were also reported from other areas (Sankar 1988; Balasubramanian \& Bole 1993; Mukherjee et al. 2004). Although a high degree of overlap was observed between these two sympatric species, there was an overall difference in dietary composition as smaller body sized rodents and birds were found more in the diet of the Jungle Cat (71\%) than in that of the Golden Jackal 


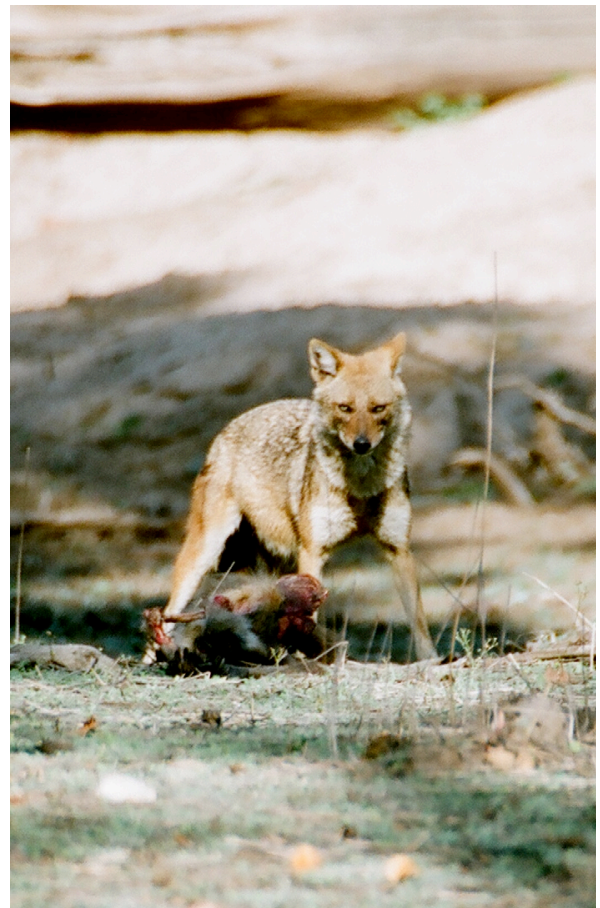

Image 2. Golden Jackal feeding on Hanuman Langur in Pench Tiger Reserve, Madhya Pradesh.

(48\%), utilization of fruits by the jackal and variation in temporal activity patterns enabled them to coexist in Pench. A long term ecological study is the need of the hour on these mesocarnivores covering population estimation, seasonal food habits and temporal activity patterns using comparable scientific methods

\section{REFERENCES}

Acharya, B.B., K. Sankar \& A.J.T. Johnsingh (2007). Ecology of the Dhole (Cuon alpinus Pallas) in Central India, Final Report, Wildlife Institute of India, Dehradun,110pp.

Andheria, A.P., K.U. Karanth \& N.S. Kumar (2007). Diet and prey profiles of three sympatric large carnivores in Bandipur Tiger Reserve, India. Journal of Zoology 273: 169-175.

Aiyadurai, A. \& Y.V. Jhala (2006). Foraging and Habitat Use by Golden Jackals (Canis aureus) in the Bhal region, Gujarat India. Journal of the Bombay Natural History Society 103(1): 1.

Balasubramanian, P. \& P.V. Bole (1993). Seed dispersal by mammals at Point Calimere Wildlife Sanctuary, Tamil Nadu. Journal of the Bombay Natural History Society 90: $33-44$.

Biswas, S. \& K. Sankar (2002). Prey abundance and food habit of tigers (Panthera tigris tigris) in Pench National Park, Madhya Pradesh, India. Journal of Zoology 256: 411-422.
Champion, H.G. \& S.K. Seth (1968). A Revised Survey of the Forest Types of India. Manager of Publications, Govt. of Indian Press, New Delhi, 404pp.

Dungariyal, N.S. (2008). Management Plan of Pench Tiger Reserve, Madhya Pradesh. Madhya Pradesh Forest Department, 233pp.

Danner, D.A. \& N. Dodd (1982). Comparison of Coyote and Gray Fox scat diameters. The Journal of Wildlife Management 46(1): 240-241.

Edgaonkar, E. (2008). Ecology of the Leopard Panthera pardus in Bori Widllife Sanctuary and Satpura National Park, India. PhD Thesis. University of Florida, 135pp.

Giannatos, G. (2004). Conservation action plan for the Golden Jackal Canis aureus L. in Greece. WWF Greece, 47pp.

Gompper, M., R. Kays, J. Ray, S. Lapoint, D. Bogan \& J. Cryan (2006). A comparison of Noninvasive Techniques to Survey Carnivore Communities in northeastern North America. Wildlife Society Bulletin 34: 1142-1151.

Green, J.S. \& J.T. Flinders (1981). Diets of sympatric Red Foxes and Coyotes in southeastern Idaho. Great Basin Natural 41: 251-254.

Johnsingh, A.J.T. (1983). Large mammalian prey-predator in Bandipur. Journal of the Bombay Natural History Society 80: $1-57$.

Karanth, U.K. \& M.E. Sunquist (1995). Prey selection by tiger, leopard and dhole in tropical forests. Journal of Animal Ecology 64(4): 439-450.

Lanszki, J. \& M. Heltai (2010). Food preferences of Golden Jackals and sympatric Red Foxes in European temperate climate agricultural area (Hungary). Mammalia 74: 267273.

Long, R.A., P. Mackay, W.J. Zielinski \& J. Ray (eds.) (2008). Non-invasive Survey Methods for Carnivores. Island Press, Washington, 400pp.

Maddock, A.H. \& M.R. Perrin (1993). Spatial and temporal ecology of an assemblage of viverrids in Natal, South Africa. Journal of Zoology 229(2): 277-287.

Mukherjee, S. (1989). Ecological separation of three sympartric carnivores in Keoladeo Ghana National Park, Rajasthan, India. MSc dissertation, Saurashtra University, Rajkot.

Mukherjee, S., S.P. Goyal \& R. Chellam (1994). Refined techniques for the analysis of Asiatic Lion Panthera leo persica scats. Acta Theriologica 39: 425-430.

Mukherjee, S., S.P. Goyal, A.J.T. Johnsingh \& M.R.P.L. Pitman (2004). The importance of rodents in the diet of Jungle Cat (Felis chaus), Caracal (Caracal caracal) and Golden Jackal (Canis aureus) in Sariska Tiger Reserve, Rajasthan, India. Journal of Zoology 262: 405-411.

Pianka, E.R. (1973). The structure of lizard communities. Annual Review of Ecological System 4: 53-74.

Prater, S. H. (1980). The Book of Indian Animals. Bombay Natural History Society, Oxford University Press, Bombay, 263pp.

Qureshi, Q., R. Gopal, S. Kyatham, S. Basu, A. Mitra \& Y.V. Jhala (2006). Evaluating Tiger Habitat at the Tehsil level. Project Tiger Directorate, Govt. of India, New Delhi 
$\&$ Wildlife Institute of India, Dehradun.

Ramesh, T., V. Snehalatha, K. Sankar \& Q. Qureshi (2009). Food habits and prey selection of Tiger and Leopard in Mudumalai Tiger Reserve, Tamil Nadu, India. Journal of Scientific Transactions of Environment and Technovation 2: $170-181$.

Reynolds, J.C. \& N.J. Aebischer (1991). Comparison and quantification of carnivore diet by faecal analysis: a critique with recommendations, based on the study of the Fox (Vulpes vulpes). Mammalian Review 21: 97-122.

Sankar, K. (1988). Some observations on food habits of Jackal (Canis aureus) in Keoladeo National Park, Bharatpur, as shown by scat analysis. Journal of the Bombay Natural
History Society 85(1): 185-186.

Schoener T.W. (1974). Resource partitioning in ecological communities. Science 185: 27-39.

Tatara, M. \& T. Doi (1994). Comparative analyses on food habits of Japanese Marten, Siberian Weasel and Leopard Cat in the Tsushima islands, Japan. Ecological research 9(1): 99-107,

Weaver, J., \& S. Fritts (1979). Comparison of Coyote and Wolf scat diameters. Journal of Wildlife Management 43: 786-788.

Zar, J.H. (1984). Biostatistical Analysis-2nd Edition. PrenticeHall, Englewood Cliffs, New Jersey, 718pp. 